\title{
IL-4 up-regulates epidermal chemotactic, angiogenic, and pro- inflammatory genes and down-regulates antimicrobial genes in vivo and in vitro: relevant in the pathogenesis of atopic dermatitis
}

\author{
Lei Bao ${ }^{1}$, Vivian Y Shi ${ }^{1}$, Lawrence S. Chan ${ }^{1,2,3}$ \\ Departments of ${ }^{1}$ Dermatology and ${ }^{2}$ Microbiology/Immunology, University of Illinois, \\ Chicago, IL; ${ }^{3}$ Medical Service, Jesse Brown VA Med Center, Chicago, IL, USA
}

Correspondence to: Lawrence S. Chan, MD

UIC-Dermatology, MC624, R380

808 S. Wood Street

Chicago, IL 60612 USA

Tel. (312) 996-6966

Fax. (312) 996-1188

E-mail: larrycha@uic.edu

\begin{abstract}
Abbreviations: AD, atopic dermatitis; AMPs, antimicrobial peptides; FBS, fetal bovine serum; HBD2, human $\beta$-defensin-2; NOS2, nitric oxide synthase 2; OSMR, oncostatin M receptor; Tg, transgenic; TLRs, Toll like receptors; for rest of the abbreviations, see table 2 and 3.
\end{abstract}

The authors state no conflict of interest. 


\begin{abstract}
Atopic dermatitis (AD) is a common chronic inflammatory skin disease. Although the pathogenesis of $\mathrm{AD}$ is not fully understood, we and others have shown that IL-4 plays a key role. In this study we aimed to identify keratinocyte genes regulated by IL-4 that may play important roles in the pathophysiology of AD. HaCat cells were treated with IL-4 at various concentrations for 24 hours, and PCR gene array on inflammation/autoimmunity was performed three times for analysis of differential gene expression. Of all the 370 genes examined, 32 and 53 genes are up- and down-regulated, respectively. Specifically related to AD, chemokines CCL3L1, CCL8, CCL24, CCL25, CCL26, CXCL6 and CXCL16 are up-regulated by IL-4. Pro-inflammatory factors, such as IL-19, IL-20, IL1 $\alpha$, IL-12R 32 , IL-25, IL-31RA, OSMR and nitric oxide synthase 2, are also up-regulated. In addition, IL-4 up-regulates VEGFA, a pro-angiogenic factor. In contrast, antimicrobial peptides (AMPs) or factors involved in APM production, such as IFN- $\kappa$, S100s, Toll-like receptors, and several chemokines are down-regulated. Similarly IL-4 also downregulates TNF- $\alpha$, lymphotoxin- $\beta$, an IgE suppressor, TNFSF18, a T-cells function regulator, and the glucocorticoid receptor. On the in vivo level, real-time RT-PCR on the selected genes confirmed that IL-4 up-regulates chemokines, proinflammatory cytokines while it suppresses AMP production related genes in the skin obtained from IL-4 Tg mice. Detailed examination of these genes will delineate their specific roles in chemotaxis, inflammation, angiogenesis and AMP production, all of which may contribute to the development and progression of $\mathrm{AD}$.
\end{abstract}


Key Words: IL-4, PCR array, Atopic dermatitis, IL-4 transgenic mice 


\section{Introduction}

Atopic dermatitis (AD), a chronic inflammatory skin disease, affects $10-20 \%$ of children and $1-3 \%$ of adults in developed countries [1]. In addition to skin manifestations, more than $50 \%$ of $\mathrm{AD}$ patients may have asthma or other atopic disorders [2]. However, the etiology and pathogenesis of AD have not been fully understood. We and others have shown that IL-4 might play an important role in the pathogenesis of AD [3-7]. Significant increase of IL-4-expressing T cells is detected in the early human AD skin lesions [8]. Through over-expressing IL-4 in the basal epidermis using a basal keratinocyte-specific keratin-14 promoter/enhancer, we have generated a mouse AD animal model, IL-4 transgenic (Tg) mice [9]. These Tg mice spontaneously develop skin lesions, which satisfy the clinical and histological diagnostic criteria for human $\mathrm{AD}$, while the non-Tg littermates are lesion-free [9]. Using these Tg mice, we have shown in vivo that IL-4 over-expression in the epidermis leads to up-regulation of several proinflammatory cytokines [7], B cell activation molecules [10], angiogenic factors [5], and critical adhesion molecules [11].

Since keratinocytes are a dominant epidermal cell type that is known to participate in immune responses [8], and they are located adjacent to the IL-4 expression milieu in both human $\mathrm{AD}$ [8] and the IL-4 Tg mice [9], we aim to identify the keratinocyte genes that are directly regulated by IL-4. Compared to the traditional hybridization-based microarray technique, PCR array method combines quantitative real-time PCR with the multiple gene analysis in a single microarray, thus providing high levels of sensitivity, reproducibility and specificity. Different from ordinary microarray analysis, it does not 
require RT-PCR confirmation. Our data showed that in the presence of IL-4, the expression of many chemotactic, pro-angiogenic and pro-inflammatory genes in cultured human keratinocytes is up-regulated, while many antimicrobial genes are downregulated. Furthermore, selected real-time RT-PCR on IL-4 Tg mice confirmed our in vitro findings.

\section{Materials and methods}

\subsection{Materials}

IL-4, cell culture medium DMEM, fetal bovine serum (FBS), charcoal stripped FBS, Penicillin/Streptomycin, nonessential amino acids and sodium pyruvate were obtained from Invitrogen (Carlsbad, CA); RNA isolation kit was from Qiagen (Valencia, CA); First strand kit, qPCR master mix, and Inflammatory Response and Autoimmunity 384HT PCR Arrays were purchased from SABiosciences (catalogue number: PAHS3803Z; Frederick, MD).

\subsection{Animals}

The IL-4 Tg mice were kept at $25 \mathrm{C}$ with a 14-h light/10-h dark cycle. Skin tissues were collected before the onset of AD. Non-Tg littermates were used as controls. All experimental procedures were performed in accordance with the principles of the National Institutes of Health Guide for the Care and Use of Laboratory Animals and were approved by the Institutional Animal Care and Use Committee of the University of Illinois at Chicago. 


\subsection{Cell culture}

Immortalized human keratinocytes, HaCat cells, were grown in DMEM medium supplemented with FBS (10\%), nonessential amino acids, and antibiotic solution and incubated in a humidified atmosphere of $5 \% \mathrm{CO}_{2}$ at $37 \mathrm{C}$. Culture media were replaced every 48 hours. Cells were treated with various concentrations of IL-4 in DMEM medium supplemented with $1 \%$ charcoal-dextran-treated FBS for 24 hours. Cells were washed twice with ice cold PBS and were then frozen at -80 C until RNA extraction.

\subsection{PCR array}

Inflammatory Response and Autoimmunity 384HT PCR Array analysis was performed according to the manufacturer's instructions. Briefly, $1 \mu \mathrm{g}$ of mRNA was extracted, DNase I digested, and reversely transcribed to cDNA. 10ul of master mix with cDNA was loaded into each well of the 384-well PCR array. The PCR reaction was run on a ABI 7900HT PCR machine. The cycling conditions were: $95^{\circ} \mathrm{C}, 10 \mathrm{~min}$; 40 cycles of $\left(95^{\circ} \mathrm{C}, 15 \mathrm{sec} ; 60^{\circ} \mathrm{C}, 60 \mathrm{sec}\right)$. The experiments were repeated three times. The raw data were analyzed by a web based Array Analysis Software provided by SABiosciences. Genes with at least 2-fold up-regulation or down-regulation in comparison to untreated cells and with a P-value of less than 0.05 were identified.

\subsection{RNA isolation and real-time RT-PCR analysis}

Total RNA from mouse skin tissues was isolated using Trizol reagent according to the manufacturer's instructions. The RT and real-time PCRs were performed as previously 
described [12]. Briefly $1 \mu \mathrm{g}$ of total RNA was reverse-transcribed and the final volume was $100 \mu \mathrm{l}$. The PCR were carried out in duplicate using a Stratagene Mx3000 real-time PCR machine (Santa Clara, CA). GAPDH was used as the internal reference. We used the standard - ddCT method to measure the relative mRNA expression. Primers synthesized by Integrated DNA Technologies (Coralville, IA) are listed in Table 1.

\subsection{Statistical analysis}

Data were examined by t-test (Figs. 1 and 2) using Prism software (GraphPad Software, Inc., San Diego, CA). Values were considered statistically significant at $P<0.05$.

\section{Results and discussion}

3.1. IL-4 regulates factors that are involved in chemotaxis in HaCat cells

As shown in table 2 and 3, IL-4 up-regulates several chemokines and related chemotactic factors, such as CCL8, CCL24, CCL25, CCL26, CCL3L1, CXCL6, CXCL16, CD74 and Stabilin 1, which attract different inflammatory cells to the skin. As eosinophil chemotactic factors, up-regulation of both CCL24 and CCL26 is associated with AD [1314]. Furthermore, CD74, which works synergically with eotaxin to activate eosinophils [15], is up-regulated by IL-4. In addition, Stabilin 1, which is known for mediating migration of lymphocytes to the draining lymph nodes and granulocytes to the inflammatory site, is also up-regulated by IL-4 in HaCat cells. Conversely, TNF superfamily 9 (TNFSF9), which has a known function of inducing eosinophil apoptosis [16], is down-regulated by IL-4, thus it further prolongs the pro-inflammatory effect of 
eosinophils. Consistent with our finding, TNFSF9 knockout mice displayed skin lesion, renal damage, lymphadenopathy, and high mortality, probably due to over-activation of $\mathrm{CD}^{+} \mathrm{T}$-cell and B-cell function [17]. Together, the up-regulation of the above group of keratinocyte-produced chemotactic factors by IL-4 might account in part for the prominent lymphocyte and eosinophil infiltration in skin lesions of human AD patients and our IL-4 Tg mice.

\subsection{IL-4 regulates factors that are involved in inflammation in HaCat cells}

Along with chemotactic factors, several proinflammatory factors, such as IL-1 $\alpha$, IL-19, IL-20, IL-25, IL-27, IL-12Rß2, IL31RA, nitric oxide synthase 2 (NOS2), oncostatin M receptor (OSMR), and SOCS2 are up-regulated by IL-4 in HaCat cells. Consistent with our findings, Renne et al. demonstrated that IL-1 in the skin is essential for the development of chronic AD [18]. Interestingly, IL-4 also down-regulates the expression of IL-1R antagonist in our study, thus leaving the IL-1 pro-inflammatory function unopposed. Recently it was reported that certain IL-12R $\beta 2$ polymorphisms are associated with $\mathrm{AD}$ [19] and this is in line with our data of its up-regulation by IL-4. More literature consistent with our data includes the report that keratinocytes derived from inflammatory skin (like AD and psoriasis) produce high amount of IL-19 and IL-20 [20]. IL-25, IL-33 and thymic stromal lymphopoetin produced by keratinocytes are known to work collectively to drive Th2 polarization [21]. This, together with our data of IL-4 upregulating keratinocyte IL-25, supports that IL-4 from Th2 cells in AD skin lesions upregulates IL-25, thus forming a positive feedback loop to further drive the Th2 pathway. IL-31 binding to its cognate receptors may induce skin inflammation and severe pruritus 
in AD patients [22]. Two IL-31 receptors, IL-31RA and OSMR, are up-regulated in keratinocytes derived from AD patients [23-24]. Our findings that IL-4 up-regulates these two components of the IL-31 receptor are also in line with the current literature. SOCS2 is undetectable in normal skin, but is weakly expressed in $\mathrm{AD}$ [25], and this is consistent with our data that IL-4 up-regulated its expressions in HaCat cells. NOS2 has been suggested to play a role in the pathogenesis of $\mathrm{AD}$ in NC/Nga mice, an AD model [26], and our data of NOS2 up-regulated by IL-4 also support this notion.

\subsection{IL-4 down-regulates antimicrobial factors in HaCat cells}

While IL-4 up-regulated chemotactic and pro-inflammatory factors produced by keratinocytes, it showed strong down-regulatory effects on antimicrobial factors. Many chemokines have a substantial microbicidal activity against numerous microorganisms including Staphylococcus aureus, a common pathogen involved in AD [27]. We found that CCL17, CCL19, CCL20, CX3CL1, CXCL11, CXCL14, S100 proteins, and Toll like receptors (TLRs) were down-regulated by IL-4. S100 proteins, structurally similar to calmodulin, are involved in a variety of biological function, such as calcium homeostasis, inflammation and inhibition of microorganisms. Two of these proteins, S100A8 and S100A12, which have been reported to be deficient in AD skin [28], are down-regulated by IL-4 in keratinocytes in our study. TLRs and human $\beta$-defensin (HBD) are two important classes of epidermal biodefense molecules and HBD2 production is dependent on TLR2, which utilizes TLR1 and TLR6 as coreceptors [29]. As both TLR1 and TLR6 are down-regulated by IL-4 in our study, it supports a notion that the presence of IL-4 reduces the skin's ability to eliminate invading pathogens. Interestingly, TLR-2 missense 
mutation is associated with AD [30]. In addition, IFN- $\kappa$, whose suppressed expression in AD is associated with low levels of antimicrobial peptides [31], and RIPK2, a signaling component in both the innate and adaptive immune pathways with ability to defend against pathogens [32], are all down-regulated by IL-4 in keratinocytes.

\subsection{Other IL-4 regulated factors in HaCat cells}

Other than regulating the keratinocyte chemotactic, pro-inflammatory, and antimicrobial factors, IL-4 is also found to influence other factors relating to immune responses. Previously we have shown that angiogenesis plays an important role in AD [5], and Zhang et al. have shown that VEGFA is up-regulated in AD lesions [33]. Our current data showed that IL-4 up-regulates VEGFA in keratinocytes, suggesting that the upregulation of VEGF in AD is at least in part due to the effect of IL-4. Interestingly, TNF superfamily 15, an inhibitor of angiogenesis [34], is down-regulated by IL-4. In addition, the following genes are down-regulated by IL-4 in HaCat cells: IL-1F8 and 9, which play roles in skin immune defense [35], adenosine A1 receptor, involved in preventing tissue damage caused by harmful circumstances [36], lymphotoxin $\beta$ (TNFSF3), an IgE suppressor [37], TNFSF18, a T-cells function regulator, and formyl peptide receptor 1, a G protein-coupled receptor involved in regulation of immune response and associated with AD development in cathepsin E null mice at lower levels [38]. For reasons yet to be determined, IL-18 is found to be reduced in young AD patients [39], and this is consistent with our findings that this gene is down-regulated by IL-4 in keratinocytes. In addition, we also found that IL-4 down-regulates the glucocorticoid receptor NR3C1, which may contribute to steroid resistance in some patients [40]. While IRF2 mutation has been 
linked to AD [41], IRF4's role in AD remains to be investigated. Interestingly, conditional knockout of AP- $2 \gamma$ resulted in defects in skin barrier functions and abnormal expression of filaggrin, repetin and SLURP1 [42]. While IL-4 has been shown to regulate filaggrin production and low filaggrin expression is associated with AD, SLURP1's role in $\mathrm{AD}$ has not been reported. In $\mathrm{AD}$ patients, surfactant protein $\mathrm{D}$ and $\mathrm{C} 3$ are dysregulated [43-45], and our PCR array study suggests that this dysregulation may be caused by IL-4.

Interestingly, the regulation of IL-13R $\alpha 2$ and TNFAIP6 by IL- 4 appears to challenge the idea that IL-4 plays an essential role in the pathogenesis of AD. In keratinocytes, both IL4 AND IL-13 bind to IL-4R $\alpha$ and IL-13R1. IL-13R $\alpha 2$, which binds to IL-13 with high affinity but lacks a significant cytoplasmic domain, has been reported as a dominant negative inhibitor for both IL-4 and IL-13 signal transduction pathways [46]. We found that IL-13R $\alpha 2$ is up-regulated by IL-4 in HaCat cells. In AD patients this gene is similarly up-regulated [47]. This maybe is due to a negative feedback mechanism, by which the keratinocytes try to minimize overwhelming IL-4 effects. Along the same line, TNFAIP6, a member of the hyaluronan-binding protein family, which has antiinflammation functions [48], is up-regulated dramatically in our PCR array study. Although CCL27 is over-expressed in AD lesions [6, 49], IL-4 appears to down-regulate it in keratinocytes. Since CCL27 is well known to be regulated by NF-אB [50], the upregulation of CCL27 observed in AD lesions may be caused by proinflammatory cytokines other than IL-4. Similarly, although the expressions of CCL28 [51], IL-16 [52], IL-21R [53], and TNF $\alpha$ [7] are up-regulated in AD, it appears that IL-4 down-regulates them in HaCat cells. 


\subsection{In vivo studies of IL-4 regulated genes using IL-4 Tg mice}

Through over-expressing IL-4 in the basal epidermis, we have generated a mouse AD animal model, IL-4 Tg mice [9]. Next we aimed to use the IL-4 Tg mice to verify whether the in vitro regulation of these genes by IL-4 also occurs in vivo. Towards that end, we collected skin tissues before the onset of AD to eliminate any possible effects of inflammation on gene regulation. Using real-time RT-PCR, we show that IL-4 upregulates CCL8, CCL24, IL-12Rß2, IL-13R $\alpha 2$, IL-25 and TNFAIP6, while it downregulates CCL17, FPR1, IL-1F9, TLR1 and S100A8 (Fig 1 and 2). Since our selected in vivo data are entirely consistent with the in vitro findings, our microarray data likely reflect the dysregulation of keratinocyte genes by high levels of IL-4 in AD.

$\mathrm{AD}$ is characterized by skin infiltration of IL-4-producing inflammatory cells and higher levels of IL-4 in the peripheral blood. High levels of IL-4, in turn, stimulate Th2 cell growth and synthesis of more IL-4, thus forming a positive feedback loop. We and others have shown that IL-4 plays an important role in the pathogenesis of AD. Using PCR array analysis, we for the first time extensively examined genes regulated by IL-4 in keratinocytes. Our data provide evidence that by up-regulating chemotactic, angiogenic, and pro-inflammatory genes in keratinocytes, IL-4 contributes directly to the AD inflammatory process. Similarly by down-regulating antimicrobial genes, IL-4 contributes indirectly to the AD inflammatory process in that it reduces skin's ability to eliminate invading pathogens, the source of persistent inflammation. Our data will hopefully pave pathways for future detailed examination of these genes, allowing 
investigators to dissect the pathophysiology of $\mathrm{AD}$ and to develop more target-specific therapeutic options for the AD patients they care. 


\section{Acknowledgments}

We are thankful to the Albert H. and Mary Jane Slepyan Endowed Fellowship (L. Bao)

and the Dr. Orville J. Stone Endowed Professorship (L.S. Chan) (University of Illinois)

for supporting this project. We thank Cecilia Chau for the technical support. 
[1] Saito H. Much atopy about the skin: genome-wide molecular analysis of atopic eczema. Int Arch Allergy Immunol 2005;137: 319-25.

[2] Kapoor R, Menon C, Hoffstad O, Bilker W, Leclerc P, Margolis DJ. The prevalence of atopic triad in children with physician-confirmed atopic dermatitis. $\mathrm{J}$ Am Acad Dermatol 2008;58: 68-73.

[3] Sehra S, Yao Y, Howell MD, Nguyen ET, Kansas GS, Leung DY, Travers JB, Kaplan MH. IL-4 regulates skin homeostasis and the predisposition toward allergic skin inflammation. J Immunol 184: 3186-90.

[4] Morioka T, Yamanaka K, Mori H, Omoto Y, Tokime K, Kakeda M, Kurokawa I, Gabazza EC, Tsubura A, Yasutomi Y, Mizutani H. IL-4/IL-13 antagonist DNA vaccination successfully suppresses Th2 type chronic dermatitis. Br J Dermatol 2009;160: 1172-9.

[5] Chen L, Marble DJ, Agha R, Peterson JD, Becker RP, Jin T, Li J, Chan LS. The progression of inflammation parallels the dermal angiogenesis in a keratin 14 IL-4transgenic model of atopic dermatitis. Microcirculation 2008;15: 49-64.

[6] Chen L, Lin SX, Agha-Majzoub R, Overbergh L, Mathieu C, Chan LS. CCL27 is a critical factor for the development of atopic dermatitis in the keratin-14 IL-4 transgenic mouse model. Int Immunol 2006;18: 1233-42.

[7] Chen L, Martinez O, Overbergh L, Mathieu C, Prabhakar BS, Chan LS. Early upregulation of Th2 cytokines and late surge of Th1 cytokines in an atopic dermatitis model. Clin Exp Immunol 2004;138: 375-87.

[8] Miraglia del Giudice M, Decimo F, Leonardi S, Maioello N, Amelio R, Capasso A, Capristo C, Capristo AF. Immune dysregulation in atopic dermatitis. Allergy Asthma Proc 2006;27: 451-5.

[9] Chan LS, Robinson N, Xu L. Expression of interleukin-4 in the epidermis of transgenic mice results in a pruritic inflammatory skin disease: an experimental animal model to study atopic dermatitis. J Invest Dermatol 2001;117: 977-83.

[10] Chen L, Lin SX, Overbergh L, Mathieu C, Chan LS. The disease progression in the keratin 14 IL-4-transgenic mouse model of atopic dermatitis parallels the upregulation of $\mathrm{B}$ cell activation molecules, proliferation and surface and serum IgE. Clin Exp Immunol 2005;142: 21-30.

[11] Chen L, Lin SX, Amin S, Overbergh L, Maggiolino G, Chan LS. VCAM-1 blockade delays disease onset, reduces disease severity and inflammatory cells in an atopic dermatitis model. Immunol Cell Biol 88: 334-42.

[12] Bao L, Tessier C, Prigent-Tessier A, Li F, Buzzio OL, Callegari EA, Horseman ND, Gibori G. Decidual prolactin silences the expression of genes detrimental to pregnancy. Endocrinology 2007;148: 2326-34.

[13] Amerio P, Frezzolini A, Feliciani C, Verdolini R, Teofoli P, De Pita O, Puddu P. Eotaxins and CCR3 receptor in inflammatory and allergic skin diseases: therapeutical implications. Curr Drug Targets Inflamm Allergy 2003;2: 81-94.

[14] Bao L, Shi VY, Chan LS. IL-4 regulates chemokine CCL26 in keratinocytes through the Jak1, 2/Stat6 signal transduction pathway: Implication for atopic dermatitis. Mol Immunol 2012;50: 91-7.

[15] Vieira-de-Abreu A, Calheiros AS, Mesquita-Santos FP, Magalhaes ES, MouraoSa D, Castro-Faria-Neto HC, Bozza MT, Bandeira-Melo C, Bozza PT. Crosstalk between 
MIF and Eotaxin in Allergic Eosinophil Activation Forms LTC4-Synthesizing Lipid Bodies. Am J Respir Cell Mol Biol.

[16] Heinisch IV, Bizer C, Volgger W, Simon HU. Functional CD137 receptors are expressed by eosinophils from patients with IgE-mediated allergic responses but not by eosinophils from patients with non-IgE-mediated eosinophilic disorders. J Allergy Clin Immunol 2001;108: 21-8.

[17] Vinay DS, Choi JH, Kim JD, Choi BK, Kwon BS. Role of endogenous 4-1BB in the development of systemic lupus erythematosus. Immunology 2007;122: 394-400.

[18] Renne J, Schafer V, Werfel T, Wittmann M. Interleukin-1 from epithelial cells fosters T cell-dependent skin inflammation. Br J Dermatol.

[19] Namkung JH, Lee JE, Kim E, Kim S, Shin ES, Cho EY, Yang JM. Association of single nucleotide polymorphisms in the IL-12 (IL-12A and B) and IL-12 receptor (IL12 Rbeta 1 and beta2) genes and gene-gene interactions with atopic dermatitis in Koreans. J Dermatol Sci 57: 199-206.

[20] Kunz S, Wolk K, Witte E, Witte K, Doecke WD, Volk HD, Sterry W, Asadullah K, Sabat R. Interleukin (IL)-19, IL-20 and IL-24 are produced by and act on keratinocytes and are distinct from classical ILs. Exp Dermatol 2006;15: 991-1004. [21] Carmi-Levy I, Homey B, Soumelis V. A Modular View of Cytokine Networks in Atopic Dermatitis. Clin Rev Allergy Immunol 2011.

[22] Sonkoly E, Muller A, Lauerma AI, Pivarcsi A, Soto H, Kemeny L, Alenius H, Dieu-Nosjean MC, Meller S, Rieker J, Steinhoff M, Hoffmann TK, Ruzicka T, Zlotnik A, Homey B. IL-31: a new link between T cells and pruritus in atopic skin inflammation. J Allergy Clin Immunol 2006;117: 411-7.

[23] Bilsborough J, Leung DY, Maurer M, Howell M, Boguniewicz M, Yao L, Storey $\mathrm{H}$, LeCiel C, Harder B, Gross JA. IL-31 is associated with cutaneous lymphocyte antigen-positive skin homing $\mathrm{T}$ cells in patients with atopic dermatitis. J Allergy Clin Immunol 2006;117: 418-25.

[24] Boniface K, Diveu C, Morel F, Pedretti N, Froger J, Ravon E, Garcia M, Venereau E, Preisser L, Guignouard E, Guillet G, Dagregorio G, Pene J, Moles JP, Yssel H, Chevalier S, Bernard FX, Gascan H, Lecron JC. Oncostatin M secreted by skin infiltrating $\mathrm{T}$ lymphocytes is a potent keratinocyte activator involved in skin inflammation. J Immunol 2007;178: 4615-22.

[25] Federici M, Giustizieri ML, Scarponi C, Girolomoni G, Albanesi C. Impaired IFN-gamma-dependent inflammatory responses in human keratinocytes overexpressing the suppressor of cytokine signaling 1. J Immunol 2002;169: 434-42.

[26] Kubo M, Kambayashi Y, Takemoto K, Okuda J, Muto M, Ogino K. Reactive nitrogen species formation in eosinophils and imbalance in nitric oxide metabolism are involved in atopic dermatitis-like skin lesions in NC/Nga mice. Free Radic Res 2005;39: 719-27.

[27] Yoshie O. Antimicrobial and related activities of chemokines. In: Moser B, Letts GL, Neote K, editors. Chemokine Biology - Basic Research and Clinical Application: Birkhäuser Verlag Basel; 2006, p. 151-164.

[28] Guttman-Yassky E, Lowes MA, Fuentes-Duculan J, Zaba LC, Cardinale I, Nograles KE, Khatcherian A, Novitskaya I, Carucci JA, Bergman R, Krueger JG. Low expression of the IL-23/Th17 pathway in atopic dermatitis compared to psoriasis. $\mathbf{J}$ Immunol 2008;181: 7420-7. 
[29] Kawai K, Shimura H, Minagawa M, Ito A, Tomiyama K, Ito M. Expression of functional Toll-like receptor 2 on human epidermal keratinocytes. J Dermatol Sci 2002;30: 185-94.

[30] Ahmad-Nejad P, Mrabet-Dahbi S, Breuer K, Klotz M, Werfel T, Herz U, Heeg K, Neumaier M, Renz H. The toll-like receptor 2 R753Q polymorphism defines a subgroup of patients with atopic dermatitis having severe phenotype. J Allergy Clin Immunol 2004;113: 565-7.

[31] Nomura I, Goleva E, Howell MD, Hamid QA, Ong PY, Hall CF, Darst MA, Gao

B, Boguniewicz M, Travers JB, Leung DY. Cytokine milieu of atopic dermatitis, as compared to psoriasis, skin prevents induction of innate immune response genes. $\mathrm{J}$ Immunol 2003;171: 3262-9.

[32] Chin AI, Dempsey PW, Bruhn K, Miller JF, Xu Y, Cheng G. Involvement of receptor-interacting protein 2 in innate and adaptive immune responses. Nature 2002;416: 190-4.

[33] Zhang Y, Matsuo H, Morita E. Increased production of vascular endothelial growth factor in the lesions of atopic dermatitis. Arch Dermatol Res 2006;297: 425-9.

[34] Zhang N, Sanders AJ, Ye L, Jiang WG. Vascular endothelial growth inhibitor in human cancer (Review). Int J Mol Med 2009;24: 3-8.

[35] Barksby HE, Lea SR, Preshaw PM, Taylor JJ. The expanding family of interleukin-1 cytokines and their role in destructive inflammatory disorders. Clin Exp Immunol 2007;149: 217-25.

[36] Ramakers BP, Riksen NP, van der Hoeven JG, Smits P, Pickkers P. Modulation of innate immunity by adenosine receptor stimulation. Shock 2011;36: 208-15.

[37] Jirapongsananuruk O, Donahue HL, Trumble AE, Leung DY. The modulation of cytokine and IgE production by tumor necrosis factor-beta in atopic dermatitis. J Invest Dermatol 2000;114: 200-3.

[38] Tsukuba T, Yanagawa M, Okamoto K, Okamoto Y, Yasuda Y, Nakayama KI, Kadowaki T, Yamamoto K. Impaired chemotaxis and cell adhesion due to decrease in several cell-surface receptors in cathepsin E-deficient macrophages. J Biochem 2009;145: 565-73.

[39] Narbutt J, Lesiak A, Sysa-Jedrzeiowska A, Zakrzewski M, Bogaczewicz J, Stelmach I, Kuna P. The imbalance in serum concentration of Th-1- and Th-2-derived chemokines as one of the factors involved in pathogenesis of atopic dermatitis. Mediators Inflamm 2009;2009: 269541.

[40] Inui S, Sumikawa Y, Asada H, Itami S. Glucocorticoid resistance in atopic dermatitis associated with decreased expression of glucocorticoid receptor-alpha in peripheral blood mononuclear cells. J Dermatol 37: 496-9.

[41] Nishio Y, Noguchi E, Ito S, Ichikawa E, Umebayashi Y, Otsuka F, Arinami T. Mutation and association analysis of the interferon regulatory factor 2 gene (IRF2) with atopic dermatitis. J Hum Genet 2001;46: 664-7.

[42] Guttormsen J, Koster MI, Stevens JR, Roop DR, Williams T, Winger QA.

Disruption of epidermal specific gene expression and delayed skin development in AP-2 gamma mutant mice. Dev Biol 2008;317: 187-95.

[43] Hohwy T, Otkjaer K, Madsen J, Soerensen G, Nielsen O, Vestergaard C, Steiniche T, Holmskov U, Lomholt H. Surfactant protein D in atopic dermatitis and psoriasis. Exp Dermatol 2006;15: 168-74. 
[44] Akman A, Kankavi O, Ciftcioglu MA, Alpsoy E. Surfactant proteins in inflammatory skin diseases: controlled study. Arch Dermatol Res 2008;300: 353-6. [45] Chiarelli F, Canfora G, Verrotti A, Amerio P, Morgese G. Humoral and cellular immunity in children with active and quiescent atopic dermatitis. Br J Dermatol 1987;116: 651-60.

[46] Wu AH, Low WC. Molecular cloning and identification of the human interleukin 13 alpha 2 receptor (IL-13Ra2) promoter. Neuro Oncol 2003;5: 179-87.

[47] Hussein YM, Ahmad AS, Ibrahem MM, Elsherbeny HM, Shalaby SM, El-Shal AS, Sabbah NA. Interleukin 13 receptors as biochemical markers in atopic patients. J Investig Allergol Clin Immunol 21: 101-7.

[48] Milner CM, Higman VA, Day AJ. TSG-6: a pluripotent inflammatory mediator? Biochem Soc Trans 2006;34: 446-50.

[49] Maeda S, Tsuchida H, Shibata S, Kawakami T, Tsukui T, Ohba Y, Fukata T, Kitagawa H. Expression analysis of CCL27 and CCL28 mRNA in lesional and nonlesional skin of dogs with atopic dermatitis. J Vet Med Sci 2008;70: 51-5. [50] Zou GM, Hu WY, Wu W. TNF family molecule LIGHT regulates chemokine CCL27 expression on mouse embryonic stem cell-derived dendritic cells through NFkappaB activation. Cell Signal 2007;19: 87-92.

[51] Kagami S, Kakinuma T, Saeki H, Tsunemi Y, Fujita H, Sasaki K, Nakamura K, Takekoshi T, Kishimoto M, Mitsui H, Komine M, Asahina A, Tamaki K. Increased serum CCL28 levels in patients with atopic dermatitis, psoriasis vulgaris and bullous pemphigoid. J Invest Dermatol 2005;124: 1088-90.

[52] Belloni Fortina A, Tonin E, Pigozzi B, Romano I, Michelotto G, Alaibac M. IL16 serum level in children with atopic dermatitis. Int J Immunopathol Pharmacol 2006;19: 841-5.

[53] Jin H, Oyoshi MK, Le Y, Bianchi T, Koduru S, Mathias CB, Kumar L, Le Bras S, Young D, Collins M, Grusby MJ, Wenzel J, Bieber T, Boes M, Silberstein LE, Oettgen $\mathrm{HC}$, Geha RS. IL-21R is essential for epicutaneous sensitization and allergic skin inflammation in humans and mice. J Clin Invest 2009;119: 47-60. 


\section{Table 1. Mouse primers used for real-time RT-PCR.}

\section{Table 2. Genes up-regulated by IL-4 in HaCat cells.}

HaCat cells were treated with various concentrations of IL-4 for 24 hours. PCR array studies were performed as described in Materials and methods. Gene names, corresponding accession numbers, abbreviations and fold change values are listed. All the fold change values are statistical significant except $\mathrm{B}$, which means $\mathrm{P}>0.05$.

\section{Table 3. Genes down-regulated by IL-4 in HaCat cells.}

HaCat cells were treated with various concentrations of IL-4 for 24 hours. PCR array studies were performed as described in Materials and methods. Gene names, corresponding accession numbers, abbreviations and fold change values are listed. All the fold change values are statistical significant except $\mathrm{B}$, which means $\mathrm{P}>0.05$.

\section{Fig. 1. Up-regulated genes in the IL-4 Tg mice.}

Tissue samples were collected from normal appearing skin of IL-4 Tg mice and non-Tg littermates. RNA extraction and real-time RT-PCR were performed as described in Materials and methods. Values are expressed as the mean $\pm \operatorname{SEM}(\mathrm{n}=3) .{ }^{*}, P<0.05 v s$. non-Tg mice.

\section{Fig. 2. Down-regulated genes in the IL-4 Tg mice.}

Tissue samples were collected from normal appearing skin of IL-4 Tg mice and non-Tg littermates. RNA extraction and real-time RT-PCR were performed as described in 
Materials and methods. Values are expressed as the mean $\pm \operatorname{SEM}(\mathrm{n}=3)$. ${ }^{*}, P<0.05 v s$. non-Tg mice. 